\title{
Research on the Impact of Environmental Regulations on China's Regional Water Resources Efficiency: Insights from DEA and Fixed Effects Regression Models
}

\author{
Manqi Zhang1, Dongfang Qiu* \\ ${ }^{1}$ College of Economics and Management, Nanjing University of Aeronautics and Astronautics, \\ No.29 Jiangjun Avenue, Jiangning District, Nanjing, China \\ ${ }^{2}$ College of Economics and Management, Nanjing University of Aeronautics and Astronautics, \\ No.29 Jiangjun Avenue, Jiangning District, Nanjing, China
}

Received: 27 July 2021

Accepted: 9 November 2021

\begin{abstract}
Using China's provincial panel data during 2006-2019, this paper attempts to research the impacts of environmental regulation on green water efficiency. A Slacks-Based Measure-Data Envelopment Analysis (SBM-DEA) model with undesirable outputs is used to evaluate green water efficiency for thirty provinces in China. The result indicates a relatively low green water efficiency and significant difference between provinces in China. We have three main findings: (1) The efficiency of green water resources in eastern China is on the rise, and there is a necessity to make further optimization. (2) Environmental regulation has a positive effect on the national green water efficiency. Because of regional differences, environmental regulation has a significant positive effect on the green water efficiency of both the east and the west, but its impact on the western green water efficiency has not passed the significance test. Still, the negative elasticity coefficient indicates that environmental regulation is not conducive to improving the efficiency of green water resources in the west. (3) As for control variables, technological progress, education input, urbanization rate, and the level of opening up facilitate more rapid the growth of green water efficiency in the east. The roles of the level of opening up, education input, and urbanization rate in improving central green water efficiency are extremely obvious. There is a negative correlation between economic development and green water efficiency in western China. Except for the abundance of water resources and foreign capital utilization of the west, the remainder of control variables shows a positive effect.
\end{abstract}

Keywords: environmental regulation, green water efficiency, sustainable development

*e-mail: qdf99@163.com 


\section{Introduction}

In the new era, General Secretary Jinping Xi has pointed out that "The transition of the Chinese economy from a phase of rapid growth to a stage of high-quality development, which demands a change in development concepts, optimization of economic structure and a shift in growth drivers, won't be easy." In 2010, in terms of nominal GDP, China ran well ahead of Japan and became the world's second-largest economy (Dong et al., 2019a [1]). From the reform and opening-up policy until now, the traditional extensive economic growth mode has made outstanding contributions to China's economic growth. Meanwhile, it has caused severe environmental pollution, resulting in a shortage of water resources, water environmental pollution, and aquatic ecosystem damage. These ecological problems lead to sustainability constraints on the development of the industry becoming tighter (Pang et al., 2015 [2]). From the overall point of view, the river pollution in China is generally in the urban section and then gradually turns from the downstream to the upstream. Under the dual effects of natural and human factors, lake eutrophication gradually becomes an increasing crisis. In addition, overexploitation of groundwater resources causes the falling of water level, resource extinction, and aggravating pollution. According to China's Gross Economic-ecological Product Accounting in 2018 issued by the Chinese Academy of Environmental Planning, China's GDP in 2015 was 72.3 trillion RMB, the cost of ecological damage was 0.63 trillion RMB, the cost of pollution loss was 2 trillion RMB, and ecosystem ecological regulation services cost 53.1 trillion RMB. Besides, living and production factors such as air, water, and land resources are constantly polluted, adversely affecting national economic production and residents' lives. How to solve the problem of water deterioration poses huge challenges for today's highquality economic development in China. Therefore, according to the Environmental Protection Industry Innovation Conference in 2018, participants pointed out that China's water pollution control had entered the most critical moment. Under the new situation, we must comprehensively enhance environmental governance to improve the efficiency of green water resources. Energy conservation and pollution emission reduction, green industry, and environmental regulation have always been the focus of scholarly studies. In the meantime, many scholars at home and abroad are constantly conducting a whole slew of research on whether water resources are exactly matched with land, agriculture, valley, population, economy, energy, and urban spatial evolution. The economic characteristics of water resources demonstrate that, as an important natural resource and an essential element for economic development, it has rareness, irreplaceability, and volatility of regenerative behavior. The contradiction between supply and demand of water resources caused by a restriction in climate, geography, and other factors is becoming deep increasingly. There are spiny problems among regions, such as uneven distribution of water resources, low per capita amount of water resources, and mismatch between economic development and water resources endowment. For instance, the western region is rich in natural resources that are difficult to develop and utilize. The fact, such as an evident spatially uneven distribution of water resources, industrial agglomeration, and the imbalance of human activity layout, is likely to lead to water scarcity in some areas and low utilization efficiency. Because of the rapid economic development and industrialization, the ecosystem in China is deteriorating at an unprecedented speed. Since the 1970s, the Chinese government whose management methods, or administration is in accordance with the law and rules has been developing a series of environmental regulations with the aim of coping with the serious pollution of the environment and endeavoring to protect our clear waters. Over the years, people in power have been committed to pursuing the harmony and unity of society and nature development and building an environment-friendly and resource-conserving society. It's essential to allocate water resources reasonably to meet the needs of production and life. As a responsible world power, the Chinese government put forward the development goals to build a country full of ecological civilization and beautification. Since the Action Plan for Prevention and Control of Water Pollution was published in 2003 and was executed in 2015, investment in industrial pollution treatment has increased. Eventually, it peaked at 68.15 billion in 2017, 62.13 billion in 2018, and 61.52 billion in 2019 . It can be seen from it that the total amount of funds used for comprehensive water resources planning is growing gradually. Therefore, the relationship between environmental regulation and green water efficiency has become the recent focus of social concern, which is beneficial to deal with increasingly serious natural resources shortage and environmental pollution. The booming of research that aims to address present dilemmas such as regional resource constraints, environmental pollution, and inefficient use of water resources, concentrates on the key factors of the solution to environmental pollution. The findings concluded in these studies are of great significance in making diverse combinations of environmental regulation tools and creating a new situation in water governance.

Environmental regulation refers to a series of restrictive measures, policies, laws, and implementation processes to achieve eco-friendly development. After the Stockholm conference on the human environment in 1972, the National People's Congress Standing Committee promulgated the Environment Protection Law of the People's Republic of China for the first time. Subsequently, new environmental laws gradually came into effect, such as the Water Pollution Control Act (1994), the Noise Pollution Control Law (1996), the Air Pollution Control Law (2000), and the Water 
Law of the People's Republic of China (2002). As laws are issued, revised, and implemented, environmental regulation has gradually been perfected. In the 1980s, China reformed the market economy, which provided the institutional basis for implementing the two significant policies: the sewage system of charges and the trade of pollutant emission. China had been collecting a pollutant discharge fee since 1982, which was the mean of market-based environmental regulation and one of the primary financial sources of funds for the supervision and pollution control of significant markets in China. As the five development concepts of "innovation, coordination, green, open, and sharing" are implemented, the environmental regulation has a closer relation with green water efficiency is expanding little by little.

Keeping a close watch on an ecological issue, people pay more attention to the connotation analysis of efficiency and choice of measuring tools in academic research. The measurement of green water efficiency should be considered from an overall perspective, including environment, society, economy, resources, and other factors. With the evolution of governance concepts in the new period, we should consider the issue of understanding the efficiency of green water resources in a more systematic, comprehensive, and objective way. Compared with the existing research, this paper makes the following contributions: (1) In the current study, most studies about water resources efficiency only represent economic benefits but ignore the characteristics of multiple attributes of water resources, especially "green development". Therefore, based on the connotation of the green development concept, this paper puts forward the "green water resources efficiency" and constructs the index of green water resources efficiency that measures the economic efficiency and the green efficiency of water resources. We establish the efficiency measurement model of green water resources that incorporates collaborative economy and ecological environment development. In the model of green water efficiency, the undesirable output factors of water environment pollution are added to solve the evaluation problem of ignoring the multiple attributes of water resources in the traditional efficiency model. (2) From this perspective, this paper discusses the efficiency level of green water resources during the investigation period from the national level and the changes in efficiency values at the regional level. (3) At the same time, the regression equation of influencing factors with double fixed effects across the whole country and various regions is constructed, which studies the driving mechanism of green water resource efficiency, discusses the differences among multiple areas, and analyzes the reasons for the differences. This paper provides a theoretical basis for further improving green water efficiency and optimizing water resources management to formulate social water-saving and emission reduction policies in the new era.

\section{Literature Review}

\section{Measurement of Water Sources Efficiency}

With the rapid development of the economy, the whole world is increasing the awareness of environmental protection, and academic studies about environmental regulation are engaged. Through literature review, it is not difficult to find that environmental regulation affects a wide range of fields, including ecological efficiency, industrial structure, total factor energy efficiency, and water resources efficiency.

Since the American operations research scientists Charnes et al. (1978) proposed the first data envelopment analysis (DEA) model [3], then it has been widely used in the study about efficiency measurements, such as energy efficiency, technological innovation efficiency, water use efficiency, and ecological efficiency (Sueyoshi and Goto, 2012 [4]; Li et al., 2022 [5]; Wang et al., 2021 [6]; Zhou et al., 2021 [7]; Deng et al., 2016 [8]; Cao et al., 2021 [9]; Luo et al., 2017 [10]). DEA is a nonparametric method that has advantages in dealing with multiple inputs and outputs, and it is unnecessary to consider model setting and the weight of input-output indicators. This evaluation method is more objective to make the calculation results more accurate and realistic. In the original DEA (CCR model) proposed by Charnes, Cooper, and Rhodes in 1978 [3], the final efficiency is obtained through the "self-evaluation" of decisionmaking units (DMU). Still, there is a certain deviation between its vale and the real one. The BCC model is often used to study the efficiency measurement, but relevant indicators laxity exists when reducing and amplifying the input-output variables. Zhang (2013) measured the financial support efficiency of eight strategic emerging industries in Suzhou based on the BBC and Tobit model [11]. On this basis, Sexton (1986) [12], Doyle and Green (1994) [13] modified the DEA model and proposed a DEA cross-efficiency approach that combined self-evaluation and peer evaluation to make the efficiency more objective and realistic. Because of its convenience, DEA has gradually become the mainstream approach for efficiency measurement in academic circles and has been improved by domestic scholars. Sun and Liu (2009) proposed DEA-ESDA to analyze the Spatial-Temporal pattern of water resources utilization efficiency [14]. Ding et al. (2018) considered undesirable outputs in the process of DEA modeling [15]. Xie and Song (2020) proposed the EBMDEA model to analyze the urban water use efficiency of the Yangtze River Economic Zone in China [16]. In order to study the driving mechanism of green efficiency of water resources in China, Sun et al. (2020) improved the DEA method based on a GWR model [17]. The DEA model combined with the hybrid network structure of the water resources system was built to evaluate the utilization efficiency of water resources (Zhang et al., 2020 [18]). 
More recently, there is a large body of empirical literature on the relationship between water resources and environmental regulation. Hu et al. (2006) first constructed the measurement model of total factor water resources efficiency based on DEA [19]. Dong et al. (2012) adopted the DEA model to discuss and analyze the water resources efficiency and input redundancy in various regions of China [20]. Some scholars mainly use DEA to incorporate undesirable outputs into the efficiency evaluation from the perspective of radial output in empirical analysis. Zhang and Zhong (2015) selected the labor force, capital, pollution emissions, and grain output factors of 31 provinces and cities in China to measure technological efficiency and total factor resource efficiency in food production from 2004 to 2013 using the SFA and DEA model [21].

Moreover, a few scholars reconstructed the NonRadical Direction Distance Function (NDDF) model that included water input and undesirable output, which provided a theoretical basis for industrial water use, regulating rivers, and green development. Sun et al. (2018) measured the urban industrial water use efficiency relying on SBM in the Yangtze River Delta Economic Zone and found that the industrial water use efficiency was low [22]. Pan et al. (2020) built the SE-SBM model to calculate the green water efficiency of 11 provinces in the Yangtze River Economic Belt during 2000-2018. What's more, these scholars found that heterogeneity exists between environmental regulation and green water efficiency in the Yangtze River Economic Belt, and the former had a positive effect on the latter [23].

SFA uses econometric methods to estimate the frontier production function and is a parametric method based on solid economic theory. Similarly, some researchers employed SFA to evaluate efficiency. While either Wang and Zhao (2008) first used the SFA model to measure China's agricultural production and irrigation water efficiency, or Karagiannis and Sarris (2004) firstly established the SFA water resources efficiency model, which contained a variety of influence factors [24]. Kaneko et al. (2004) adopted the SFA model to measure agricultural water resources efficiency of six regions and claimed that the efficiency of northwest China was the highest, and that of south China was the lowest [25]. Chen and Bai (2013) used Stochastic Frontier Analysis (SFA) to measure China's industrial total factor water resources efficiency [26]. Zhang et al. (2020) constructed a RAM-SFA-RAM three-stage measurement model of industrial green total factor water resources efficiency. With the deepening of research, the Tobit model was used to verify that factors, such as enterprise technological innovation, water structure, and environmental regulation, were propitious to industrial green total factor water resources efficiency. There were significant differences in the water resources efficiency of each zone [27].

\section{Influence Factors of Water Source Efficiency}

Existing research has revealed the influencing factors of green water efficiency from different perspectives, including theoretical research and practical analysis. Among the studies on water resources, Zhang and $\mathrm{Yu}$ (2012) used the Gini coefficient to introduce the matching degree of development and water resources in the Yellow River Basin. In conclusion, an exact match between water resources and socioeconomic in space and time is of great significance for the coordinated development in the Yellow River Basin [28]. Chen and Bai (2013) proved that regional economic development, industrial proportion, and technological development were positively related to water resources efficiency [29]. Zhang et al. (2014) used DEA to illustrate the spatial variations in urban resource and environmental efficiency (REE), and results demonstrate that REE is affected by the economy, population-scale, and urbanization rate [30]. Due to imperfect measurement modes and immature theories, the effect of environmental regulation policies is uncertain. Few scholars come up with irrefutable answers. Environmental regulation policies affect the production cost of enterprises and the total output efficiency. In order to create a more environmentally friendly production mode and avoid being eliminated by their competitors, enterprises who endeavor to improve resources utilization efficiency continue to push their technology advancing, create a more environmentally friendly production mode. By controlling the discharge of pollutants in the production process and optimizing the internal industrial structure, entrepreneurs seek a "win-win" situation to develop further. Different categories of environmental regulation have certain heterogeneity and "porter hypothesis" that the existing environmental regulation policies, guidance strategy, and unique internal design are too general to be implemented fully according to circumstances. Therefore, the effect of environmental regulation on green water efficiency needs further research.

Green water efficiency is divided into two categories: absolute efficiency and relative efficiency. Absolute efficiency refers to the efficiency that can be improved by adopting water-saving technology. By comparison, relative efficiency that is quite common in the usual study equals the regional green water efficiency based on the common frontier. China's green water efficiency involved in this paper belongs to relative efficiency. Combing the above literature, we find that the measurement method of the green water resources is mainly DEA and SFA. By analysis, the general characteristic of two mainstream approaches is to use the optimal economic unit to build a frontier for efficiency evaluation.

Nevertheless, a severe limitation of the SFA model is that the specific form must be known in the efficiency evaluation process, and it could only evaluate the efficiency of decision-making units with multiple 
inputs and a single output. In contrast, the DEA method belongs to a nonparametric productivity method, so it does not need to set a specific function appropriate for border production functions of multi-input and multioutput. Because of input redundancy and output lack, the regional green water efficiency of decision-making units is often overestimated in the ordinary DEA model. The DEA-SBM model suitable for this study is constructed in this paper, comprehensively considering the problems caused by the radial model and constrained condition relaxation. We also analyze what causes the differences in the green water efficiency of the Chinese 30 regions. Then, a regression model is established to test the effects of multiple influencing factors on green water efficiency.

\section{Discussion of the Present Research and Innovation}

Domestic and foreign scholars have done much research on water resources efficiency and have made some achievements that lay a specific theoretical foundation for our research on the measurement and influencing factors of green water resources efficiency in China. However, by summarizing current literature at home and abroad, it is necessary to study research content and methods further.

Existing research on efficiency is generally criticized on the basis of the following drawbacks. Firstly, scholars have established and developed all factor water resources efficiency that can be applied to measure the effective utilization of water resources and provide a basis for the government to formulate watersaving objectives and relevant policies. Nevertheless, in some ways, the water pollution problem goes unrecognized. Research fails to reflect the idea of sustainable development, and no more attention focuses on "green development." Secondly, most studies mainly make efforts in the water resources efficiency of agriculture and industry, lacking investigation on the green water efficiency of the whole society. Thirdly, some empirical studies analyze overall green water resources efficiencies. Further studies for identifying and formulating the promotion strategy of green water efficiency in different regions are warranted.

In order to solve the shortcomings of the existing research, this paper has several innovations. In the measurement of water resources efficiency, based on the three requirements: economic development, water resources conservation, and water pollution control, the model made to measure green water resources efficiency takes water pollution as an unexpected output, which reflects the requirements of sustainable development and focuses on integrative consideration of economic benefit and ecological benefit. Economic benefit refers to the positive supporting effect of water resources investment on economic growth mode. Moreover, the ecological benefit is reflected in the efficiency of water resources utilization and water environmental pollution control effort in the production process.

In terms of the impact of water resources efficiency, combined with the existing research literature, the possible influencing factors such as industrial structure, aggregate economy, technology, and education are selected into the control variables to distinguish these factors' performance effectively.

Finally, the empirical study analyzes the green water efficiency and influencing factors of the whole society. Then, the whole country is divided into three regions to explore the differences in green water efficiency and the effects of influencing factors. The more mature measurement indicators and empirical are, the more scientific and comprehensive the conclusions become.

\section{Methods}

\section{Green Water Efficiency Measurement Model}

The SBM model was first introduced by Tone and Sahoo (2003), and the target function included slack variables directly different from DEA tradition modes [31]. Based on the connotation of green development, the "green water efficiency" model is created, and the SBM model is used to measure green water efficiency.

Suppose that each province is a decision-making unit, and there are $n$ decision-making units. There are $m$ input variables $(x)$, including labor, capital, and water resources. Desirable output and undesirable output variables will be produced, as shown in Table 1 . Respectively, $x \in R^{m}, y^{g} \in R^{S_{1}}, z^{b} \in R^{S_{2}}$. Define the matrix $X, Y^{g}, Z^{b}$ as $X=\left(x_{i, j}\right) \in R_{m \times n}, Y^{g}=\left(y^{g}{ }_{i, j}\right) \in R_{S_{1 \times n}}$, $Z^{b}=\left(z_{i, j}^{b}\right) \in R_{S 2 \times n}$. Among them, $X>0, Y^{g}>0, Z^{b}>0$, the production possibility set is as follow:

$T=\left\{\left(x, y^{g}, z^{b}\right): x\right.$ can produce $\left.\left(y^{g}, z^{b}\right), \mathrm{x} \in \mathrm{R}^{\mathrm{m}}, \mathrm{y}^{\mathrm{g}} \in R^{s 1}, \mathrm{z}^{\mathrm{g}} \in R^{s 2}\right\}$

The SBM model formula is as follows:

$$
\begin{gathered}
\rho^{*}=\min \frac{1-\frac{1}{m} \sum_{i=1}^{m} s_{i}^{-} / x_{i o}}{1+\frac{1}{s_{1}+s_{2}}\left(\sum_{j=1}^{s} s_{j}^{g} / y_{j 0}^{g}+\sum_{k=1}^{s_{2}} s_{k}^{b} / z_{k 0}^{b}\right)} \\
\text { s.t }\left\{\begin{array}{l}
x_{0}=x \lambda+s^{-}, y_{0}^{g}=y^{g} \lambda-s^{g}, z_{0}^{b}=z^{b} \lambda+s^{b} \\
s^{-} \geq 0, s^{g} \geq 0, \quad s^{b} \geq 0, \lambda \geq 0
\end{array}\right.
\end{gathered}
$$

Where $\rho^{*}$ is the green water efficiency value for DMU $\left(X_{0}, Y_{g}, Z_{b}\right)$. Among them, the value range of an objective function $\rho$ is $0<\rho \leq 1 ; x$ indicates inputs, $y^{g}$ and $z^{b}$ respectively refer to desirable outputs and undesirable outputs; $s^{-}, s^{g}$ and $s^{b}$ represent the slack of inputs, desirable outputs and undesirable outputs, which refer to the inefficient part in production. The slack of inputs means the redundant part of input that cannot participate in production effectively. The slack 
of desirable outputs refers to the shortage of effective output, and that of undesirable outputs is the excessive pollution emissions occurring during the production process. $m, s_{1}$ and $s_{2}$ are the quantity of input, desirable and undesirable outputs respectively; $\lambda$ is the weight vector.

\section{Green Water Efficiency Influence Factors Regression}

This paper uses the panel data regression model to analyze the effect of environmental regulation and other relative factors on green water efficiency.

$$
G W E_{i t}=\alpha+\beta e r_{i t}+\lambda C+\eta_{i}+\mu_{t}+\varepsilon_{i t}
$$

GWE (Green Water Efficiency) is the explained variable. In function (3), $i$ refers to time, $t$ represents regions, $e r$ is the explanatory variable that is environmental regulation, and $C$ represents variables which need to be controlled in the function; Then, $\eta_{i}$ is the individual effect, $\mu_{t}$ is the time effect, $\varepsilon_{i t}$ is the random effect. Furthermore, the impact degree of environmental regulation on green water efficiency is represented by $\beta$.

Combined with the explanatory variables selected in this paper, the regression model built in this paper is as follows:

$$
\begin{gathered}
G W E_{i t}=\alpha+\beta e r_{i t}+\lambda_{1} \ln g d p+\lambda_{2} \operatorname{lnsup}+\lambda_{3} \ln f d i+\lambda_{4} \operatorname{lntec} \\
+\lambda_{5} u r b+\lambda_{6} \operatorname{sip}+\lambda_{7} \text { tip }+\lambda_{8} e d u+\varepsilon_{\mathrm{i}}
\end{gathered}
$$

\section{Variables}

The measurement of green water efficiency requires the selection of appropriate indicators. Based on the production function created by Cobb-Douglass, Wang et al. (2002) improved the efficiency measurement model [32]. This paper selects labor, capital, and water resources as input. Capital is measured by the fixed capital stock calculated by the fixed capital formation index based on the year 2001 with the perpetual inventory method according to the paper written by Zhang (2004) [33]. The formula is $K_{j t}=K_{j t-1}\left(1-\delta_{j t}\right)+I_{j t}$, where $K_{j t}$ is the fixed capital stock of the $j$ th province in the $t$ th year, $I_{j t}$ is the fixed capital formation of the $j t h$ province in the $t$ th year, and $\delta_{j t}$ is the depreciation rate of fixed capital of the province in the $t$ th year. Desirable output is measured by the gross region domestic product with the GDP deflator of 2001. Undesirable output is discarded water. The index system is shown in Table 1.

In this article, taking a lesson from the relevant domestic and foreign research, we will discuss the effect of marked-based environmental regulation measured by pollutant discharge fees. Collecting pollutant discharge fees is the primary market-based environmental regulation method that makes enterprises consider pollution control when producing.

There are seven control variables considered in this paper. Firstly, economic development level (gdp) is measured by gross regional domestic product with the GDP deflator of 2001. Secondly, an urbanization rate (urb) describes the percentage of non-agricultural urban pollution to the total population. Thirdly, utilization of foreign capital (fdi) adopts the ratio of the actual used foreign capital to gross regional domestic product to judge opening up level. Fourthly, education input (edu) is the ratio of provincial education expenditure to the real GDP per capita of each province; Fifthly, technological progress (tec) is defined as the percentage of funding for research and experimental development to the gross regional product. Sixthly, the industrial structure is expressed by the proportion of the secondary (sip) and tertiary (tip) industries in GDP. Finally, water resources abundance (sup) is measured by the total amount of water resources per capita in each province.

\section{Data Source}

In this paper, the thirty provinces in China are taken as study objects. Due to the lack of data, Tibet, Hong Kong, Macao, and Taiwan are not considered. The time is from 2006 to 2019 by combining with the situation of data acquisition. The research data is mainly collected from China Statistical Yearbook, China Environmental Statistical Yearbook, China Environmental Statistical Yearbook, China Industrial Statistical Yearbook, China Water Resources Bulletin, China Science and Technology Statistical Yearbook, regional statistical yearbooks, natural resources and environment statistical yearbooks, and statistical bulletins. In addition, indicators designed to measure

Table 1. Regional green water efficiency evaluation index system.

\begin{tabular}{|c|c|c|c|}
\hline & Index category & Index form & Unit \\
\hline \multirow{2}{*}{ Input index } & Labor $\left(\mathrm{X}_{1}\right)$ & Quantity of employment & 10,000 people \\
\cline { 2 - 4 } & Capital $\left(\mathrm{X}_{2}\right)$ & Capital stock & RMB 10 million yuan \\
\cline { 2 - 4 } & Water sources $\left(\mathrm{X}_{3}\right)$ & Water consumption & $10 \mathrm{million}^{3}$ \\
\hline Desirable output index & Total output $(\mathrm{Y})$ & Regional GDP & RMB 10 million yuan \\
\hline Undesirable output index & Water pollution $(\mathrm{Z})$ & Total waste water discharge & 10,000 ton \\
\hline
\end{tabular}


currency, such as the capital stock of provinces, are measured with the GDP deflator of 2001 in order that the influence of price factors is eliminated. The missing data in some regions are estimated by moving average.

\section{Result}

\section{Green Water Efficiency at National Level}

According to the classification standards of the National Bureau of Statistics, China's thirty-one provinces are divided into three groups: eastern, western, and central. Because of a lack of complete data, some areas are removed, such as Tibet. The DEA-SBM model is used to measure the green water efficiency of thirty provinces in China from 2006 to 2019 and then average out the efficiency of each province to obtain the green water efficiency at the regional level. The specific values are exhibited in Table 2, and the trend is plotted as shown in Fig. 1.

As seen in Table 2, national green water efficiency generally fluctuated upward, and the average annual growth rate is $2.14 \%$. The fact indicates that for a long time before 2019, with the rapid development of economic society in the macro-control of government, green water comprehensive management was strengthened as expected, and the green water efficiency had been continuously going up. Moreover, Fig. 1 demonstrates the features of phased change for the green water efficiency at the national level experiences three stages: vibration decline, stabilization, and, acceleration. From 2006 to 2009, the efficiency showed a decreasing trend, and in 2009, green water efficiency was at its lowest (0.464), with an average annual growth rate of $-1.6 \%$. In the fall of 2008, many countries got caught in the global financial fallout. During this period, the domestic economy sagged. An import-export business suffered huge losses in the teeth of the worst crisis as well. The problems, such as inflation, business bankruptcy, and weak investment, dealt a blow to the development of the whole society. Because input and output were affected by financial crisis, green water efficiency decreased to some extent. In the wave of global economic recession, facing the grim international and domestic situation, China adjusted its macroeconomic policies flexibly and decisively and made use of the "stimulus package" to make the domestic economy recover and develop stably, which significantly reduced the loss of China in this crisis. In 2009-2013, green water efficiency entered a phase of steady growth when the economy picked up, and its average annual growth rate was $1.11 \%$.

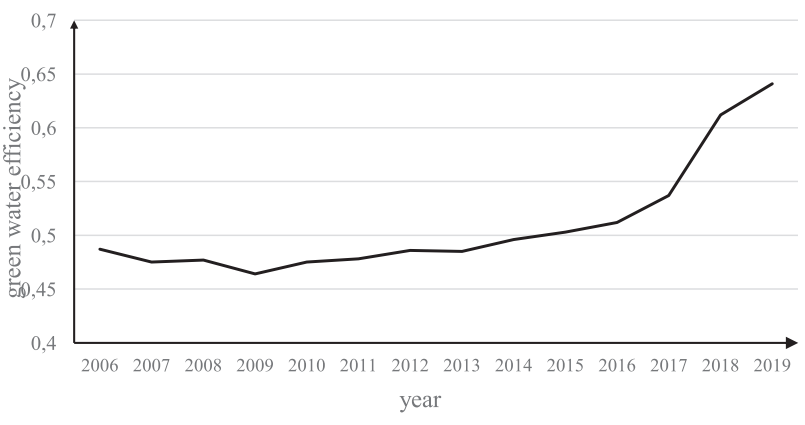

Fig. 1. The change trend for the national green water efficiency.

On the contrary, the efficiency did not improve significantly, possibly constrained by resources and the environment. Another reason was that the economic development mode of labor-intensive and resourceintensive enterprises had not been fundamentally changed. Therefore, after a short-term fluctuation, the efficiency got back to a stable growth track. Notably, in 2013, green water efficiency struggled during a particular segment of upper initiation, and its value was greatly improved, with a growth rate of $14 \%$ in 2018 . During 2017-2019, the average annual growth rate was $9.26 \%$. The development tendency would suffice to prove that "improving quality and reducing emission" became the leading tone of the macro-economy. Environmental tax and pollution permission management regulations motivated enterprises, especially heavily-polluting industries, to accelerate industrial transformation and take advantage of energy-saving and low-carbon technologies. Resources saving and environmentally friendly economic development have gradually become the main direction of industrial structure adjustment and upgrading. In the implementation of laws, regulations and policies, government and society should pay more attention to industries and enterprises that are experiencing technological progress. From 2006 to 2019 , the green water efficiency of most provinces in China had different degrees of improvement, and made an overall leap.

From 2006 to 2019, the green water efficiency of most provinces in China had different degrees of improvement, and made an overall leap.

Fig. 2 shows the change trend of water input redundancy in China from 2006 to 2019. Concluded from Fig. 2, national water input redundancy decreases in a fluctuation, with an average annual growth rate of $-2.7 \%$. We can see that input redundancy decreased from 2006 to 2008, and the growth rate in 2008 was $-4.4 \%$. The international financial crisis that broke out in 2008 impacted the production of society.

Table 2. Green water efficiency of the whole country.

\begin{tabular}{|c|c|c|c|c|c|c|c|c|c|c|c|c|c|c|}
\hline Year & 2006 & 2007 & 2008 & 2009 & 2010 & 2011 & 2012 & 2013 & 2014 & 2015 & 2016 & 2017 & 2018 & 2019 \\
\hline The whole country & 0.487 & 0.475 & 0.477 & 0.464 & 0.475 & 0.478 & 0.486 & 0.485 & 0.496 & 0.503 & 0.512 & 0.537 & 0.612 & 0.641 \\
\hline
\end{tabular}


In the case, output of enterprises was restrained to some extent. Kinds of productive factors were out of use, then correspondingly input redundancy increased, and the allocation efficiency of water resources was low. The situation of waste and pollution were serious. Judging from 2009, the investment was in a stable decline state. The input redundancy greatly reduced in 2016 and the average annual growth rate between 2016 and 2018 was $-12.41 \%$. Since it was listed as the top of the seven emerging strategic industries, the environmental protection industry roared ahead, and soon new environmental policies were promulgated frequently. Environmental legislation was standardized and perfected gradually. Moving forward with the $13^{\text {th }}$ Five-Year Plan, green tariff, and the policy of red lines for ecological protection, ministry of environment protection did everything in its power to push forward the formulation and revision of approximate 900 environmental protection standards, which provided the basis for laws supervision and enforcement. Moreover, with the establishment of stationary source management system that took pollutant discharge permit system as the core, the level of social production would be increased, and the green water efficiency would be-lied several times.

In this context, the average slack quantity of water input of the eastern region in the past 14 years had arrived at 840,300 tons. The line of water input slack in eastern China exhibits a downward trend as a whole. The slack quantity of water input in the central region fluctuated during the investigation period but increased after decreasing in 2008 and finally decreased significantly in 2018. In contrast, the redundant amount of water resources in the western region increased slightly, and the changing trend of each year was relatively stable.

Fig. 3 shows the trend of the slack quantity of polluted water in the country within 14 years. As a whole, from 2006 through 2019, the national sewage discharge redundancy mainly was on the decline, the trend of whom fluctuated steadily in the early part, and began to decrease in 2012. From the results described above, we discover that there is some potential for the development of water resources protection at a pace with great strides in environmental governance and economic development. Wastewater emission redundancy decreased in 2015, a pretty steep drop, and remained negative in 2019, with an average annual growth rate of $-10 \%$ from 2012 to 2019 . Although the redundancy of input and sewage discharge are decreasing, there is still a great potential for green development and the management of water resources.

The changing trend of polluted water slack quantity is consistent with water input slack quantity in different areas. The eastern region has decreased year by year, and the central region has increased slightly and then decreased in 2013. The western region has been on the rise for the whole 14 years.

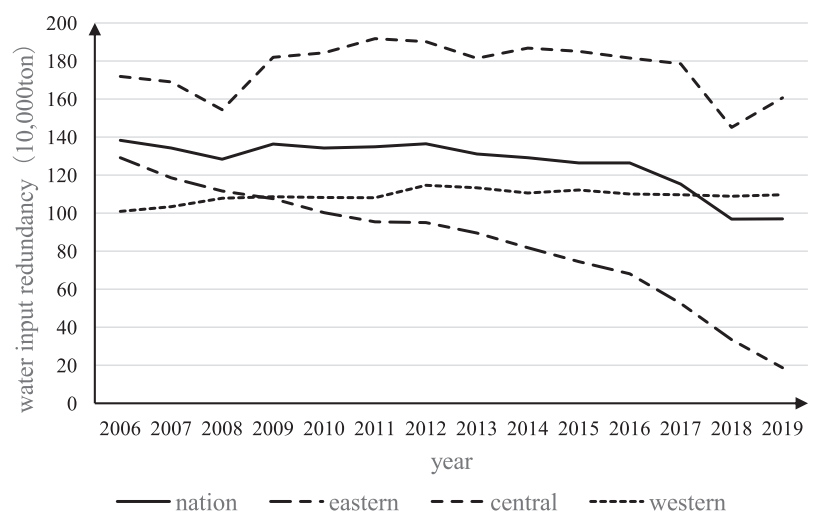

Fig. 2. The trend of national and regional water input slack quantity.

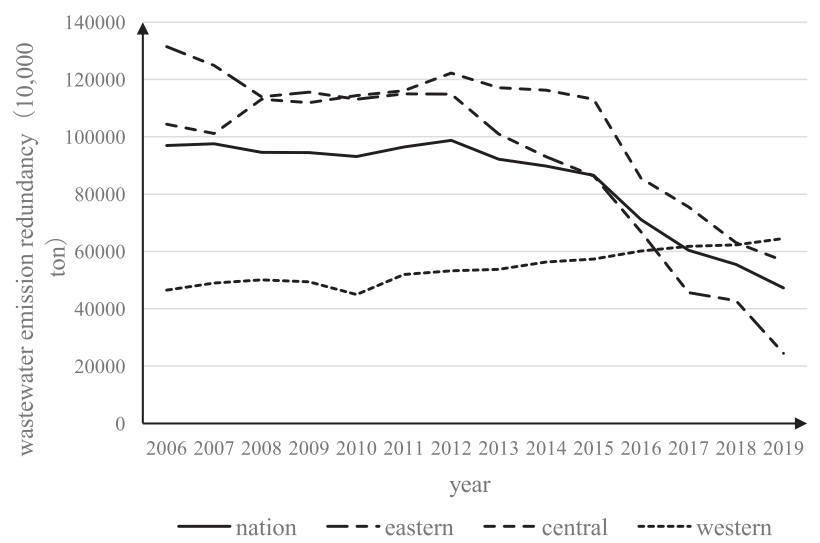

Fig. 3. The trend of national and regional polluted water slack quantity.

\section{Green Water Efficiency at Regional Level}

In this chapter, regional changes in green water efficiency are further analyzed. Tables 3-5 shows the value of green water efficiency in three regions from 2006 to 2019, while the efficiency changes of the whole country and each region are depicted in Fig. 4 below.

According to Fig. 4 and Tables 3-5, the efficiency of the eastern, central, and western regions has local

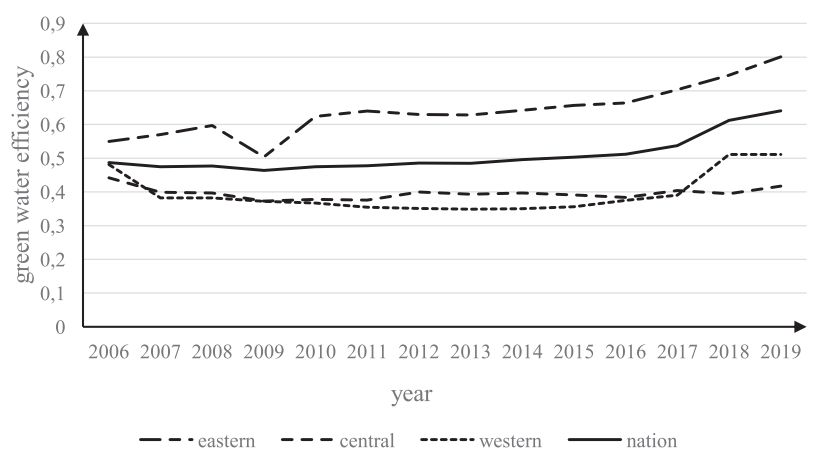

Fig. 4. The change trend of green water efficiency in different regions. 
Table 3. Green water efficiency of eastern region.

\begin{tabular}{|c|c|c|c|c|c|c|c|c|c|c|c|c|c|c|}
\hline Region & 2006 & 2007 & 2008 & 2009 & 2010 & 2011 & 2012 & 2013 & 2014 & 2015 & 2016 & 2017 & 2018 & 2019 \\
\hline Beijing & 0.577 & 0.612 & 0.648 & 0.642 & 0.698 & 0.749 & 0.773 & 0.780 & 0.786 & 0.799 & 0.781 & 0.855 & 0.929 & 1.000 \\
\hline Tianjin & 1.000 & 1.000 & 1.000 & 1.000 & 1.000 & 1.000 & 1.020 & 1.000 & 1.000 & 0.947 & 1.000 & 0.964 & 0.971 & 1.000 \\
\hline Hebei & 0.368 & 0.355 & 0.358 & 0.358 & 0.371 & 0.375 & 0.375 & 0.381 & 0.384 & 0.399 & 0.427 & 0.476 & 0.507 & 0.568 \\
\hline Liaoning & 0.459 & 0.456 & 0.456 & 0.442 & 0.481 & 0.488 & 0.492 & 0.505 & 0.500 & 0.522 & 0.534 & 0.564 & 0.615 & 0.669 \\
\hline Shanghai & 0.470 & 0.549 & 0.588 & 0.581 & 0.624 & 0.646 & 0.695 & 0.751 & 0.940 & 1.000 & 0.853 & 0.879 & 0.948 & 1.000 \\
\hline Jiangsu & 0.331 & 0.338 & 0.373 & 0.354 & 0.416 & 0.457 & 0.504 & 0.555 & 0.609 & 0.670 & 0.735 & 0.834 & 0.920 & 1.000 \\
\hline Zhejiang & 0.356 & 0.363 & 0.391 & 0.375 & 0.405 & 0.428 & 0.444 & 0.464 & 0.507 & 0.562 & 0.618 & 0.670 & 0.733 & 0.800 \\
\hline Fujian & 0.394 & 0.384 & 0.390 & 0.387 & 0.410 & 0.394 & 0.419 & 0.431 & 0.440 & 0.453 & 0.480 & 0.501 & 0.490 & 0.565 \\
\hline Guangdong & 0.659 & 1.000 & 1.000 & 0.844 & 0.947 & 1.000 & 1.000 & 1.000 & 1.000 & 0.978 & 1.000 & 1.000 & 1.000 & 1.000 \\
\hline Hainan & 1.000 & 1.000 & 1.000 & 0.983 & 1.000 & 1.000 & 0.799 & 0.691 & 0.622 & 0.617 & 0.598 & 0.594 & 0.604 & 0.622 \\
\hline Shandong & 0.387 & 0.389 & 0.424 & 0.408 & 0.463 & 0.501 & 0.541 & 0.574 & 0.624 & 0.680 & 0.762 & 0.849 & 0.931 & 1.000 \\
\hline Eastern & 0.550 & 0.570 & 0.597 & 0.504 & 0.624 & 0.640 & 0.630 & 0.628 & 0.642 & 0.657 & 0.664 & 0.703 & 0.746 & 0.801 \\
\hline
\end{tabular}

Table 4. Green water efficiency of central region.

\begin{tabular}{|c|c|c|c|c|c|c|c|c|c|c|c|c|c|c|}
\hline Region & 2006 & 2007 & 2008 & 2009 & 2010 & 2011 & 2012 & 2013 & 2014 & 2015 & 2016 & 2017 & 2018 & 2019 \\
\hline Shanxi & 0.398 & 0.368 & 0.369 & 0.368 & 0.371 & 0.368 & 0.373 & 0.379 & 0.378 & 0.373 & 0.383 & 0.389 & 0.397 & 0.400 \\
\hline Jilin & 0.457 & 0.409 & 0.387 & 0.396 & 0.377 & 0.375 & 0.384 & 0.387 & 0.382 & 0.379 & 0.422 & 0.408 & 0.421 & 0.435 \\
\hline Heilongjiang & 0.597 & 0.581 & 0.545 & 0.589 & 0.538 & 0.471 & 0.416 & 0.419 & 0.417 & 0.425 & 0.449 & 0.469 & 1.000 & 0.752 \\
\hline Anhui & 0.379 & 0.353 & 0.354 & 0.357 & 0.362 & 0.346 & 0.348 & 0.346 & 0.352 & 0.350 & 0.367 & 0.381 & 0.392 & 0.409 \\
\hline Jiangxi & 0.358 & 0.322 & 0.333 & 0.333 & 0.337 & 0.325 & 0.333 & 0.326 & 0.322 & 0.348 & 0.354 & 0.376 & 0.391 & 0.405 \\
\hline Henan & 0.365 & 0.328 & 0.308 & 0.321 & 0.308 & 0.307 & 0.303 & 0.302 & 0.319 & 0.322 & 0.348 & 0.376 & 0.413 & 0.450 \\
\hline Hubei & 0.313 & 0.299 & 0.314 & 0.308 & 0.325 & 0.322 & 0.328 & 0.324 & 0.327 & 0.340 & 0.362 & 0.372 & 0.387 & 0.403 \\
\hline Hunan & 0.336 & 0.322 & 0.329 & 0.329 & 0.332 & 0.333 & 0.330 & 0.328 & 0.334 & 0.342 & 0.354 & 0.371 & 0.387 & 0.407 \\
\hline Central & 0.442 & 0.399 & 0.395 & 0.373 & 0.378 & 0.376 & 0.400 & 0.393 & 0.397 & 0.391 & 0.384 & 0.404 & 0.395 & 0.417 \\
\hline
\end{tabular}

Table 5. Green water efficiency of central region.

\begin{tabular}{|c|c|c|c|c|c|c|c|c|c|c|c|c|c|c|}
\hline Region & 2006 & 2007 & 2008 & 2009 & 2010 & 2011 & 2012 & 2013 & 2014 & 2015 & 2016 & 2017 & 2018 & 2019 \\
\hline Guangxi & 0.343 & 0.291 & 0.273 & 0.287 & 0.255 & 0.250 & 0.244 & 0.249 & 0.253 & 0.257 & 0.269 & 0.283 & 0.297 & 0.309 \\
\hline $\begin{array}{c}\text { Inner } \\
\text { Mongolia }\end{array}$ & 0.500 & 0.446 & 0.446 & 0.442 & 0.423 & 0.425 & 0.432 & 0.427 & 0.415 & 0.427 & 0.450 & 0.472 & 0.504 & 0.538 \\
\hline Chongqing & 0.442 & 0.377 & 0.384 & 0.373 & 0.414 & 0.451 & 0.476 & 0.488 & 0.509 & 0.532 & 0.519 & 0.540 & 0.541 & 0.544 \\
\hline Sichuan & 0.308 & 0.322 & 0.337 & 0.326 & 0.354 & 0.369 & 0.380 & 0.385 & 0.389 & 0.387 & 0.394 & 0.406 & 0.439 & 0.482 \\
\hline Guizhou & 0.394 & 0.343 & 0.350 & 0.347 & 0.354 & 0.364 & 0.351 & 0.351 & 0.330 & 0.321 & 0.322 & 0.309 & 0.302 & 0.298 \\
\hline Yunnan & 0.393 & 0.340 & 0.353 & 0.349 & 0.347 & 0.315 & 0.307 & 0.304 & 0.294 & 0.284 & 0.281 & 0.282 & 0.286 & 0.292 \\
\hline Shanxi & 0.398 & 0.368 & 0.369 & 0.368 & 0.371 & 0.368 & 0.373 & 0.379 & 0.378 & 0.373 & 0.383 & 0.389 & 0.397 & 0.400 \\
\hline Gansu & 0.548 & 0.468 & 0.415 & 0.427 & 0.413 & 0.399 & 0.400 & 0.399 & 0.398 & 0.396 & 0.399 & 0.410 & 0.418 & 0.444 \\
\hline Qinghai & 1.024 & 1.000 & 1.000 & 0.770 & 0.793 & 0.773 & 1.000 & 0.934 & 1.000 & 0.928 & 0.849 & 1.000 & 0.878 & 1.016 \\
\hline Ningxia & 0.605 & 0.477 & 0.438 & 0.466 & 0.429 & 0.422 & 0.426 & 0.410 & 0.405 & 0.421 & 0.422 & 0.437 & 0.416 & 0.433 \\
\hline Xinjiang & 0.337 & 0.293 & 0.301 & 0.299 & 0.301 & 0.302 & 0.290 & 0.277 & 0.270 & 0.267 & 0.270 & 0.263 & 0.929 & 1.000 \\
\hline Western & 0.481 & 0.382 & 0.382 & 0.372 & 0.367 & 0.355 & 0.351 & 0.349 & 0.350 & 0.356 & 0.375 & 0.390 & 0.511 & 0.511 \\
\hline
\end{tabular}


fluctuations. In eastern China, the whole variant trend is on the rise, revealing an apparent leading advantage in comparison to the two others. In 2006-2008, the efficiency value continued to increase. However, it reached the lowest point $(0.504)$ in 2009 , coning out significantly ahead. The efficiency of the eastern region showed the inverse U-shaped curves from 2008 to 2010. Under the adjustment of policies and government strategic macro-control, the green water efficiency that crashed hard rebounded smartly and nudged up stably in 2010-2017, significantly higher than the national average. After 2017, the efficiency increased obviously, with an average growth rate of $6.74 \%$. The water resources efficiency in the eastern had somewhat similar periodic characteristics, compared with the national efficiency. After experiencing the downturn in 2008, the green water efficiency recovered, developed steadily, and increased significantly after 2017. In recent years, green water efficiency of the central region had a fluctuating downward trend. The difference in green water efficiency between the central and western regions was trivial, but generally, the efficiency of the western was lower than that of the central. As seen in Tables 3-4, the green water efficiency of Beijing, Tianjin, Shanghai, Hainan, Guangdong, and Qinghai was higher than that of other cities and the whole country. In Fig. 4, the central efficiency curve was laid crosswise to the western. Except for a few years in 2006-2016, the green water efficiency value of the western region was higher than that of the central region. Conservation of water and forest resource was abundant in the central. Nevertheless, in a word, the changes of both were small and tended to be stable. Of particular concern was that in 2018, the efficiency of the western region was in a chase, increasing to 0.512 , and the average growth rate reached $31 \%$.

\section{Unit Root Test}

With the aim of avoiding "pseudo regression" results, this paper use a unit root test for data stationary to test the selected variables. HT is the test of sections with the same unit root, and IPS is used for sections different unit-roots. The two methods suitable for this reasearch are selected to inspect whether there are unit roots in each panel data. As shown in Table 6, the economic development level, opening-up level, technological progress, and urbanization rate fail to pass the HT test, and the sequence is non-stationary. After adding the first-order difference, we find they all pass the significance test at the $1 \%$ level, a stationary sequence.

\section{Cointegration Test}

In order to discuss the possibility of using the original sequence for regression analysis, we further test whether there is a long-term equilibrium relationship among unit root variables. Here, this paper uses the Kao test and Pedroni test to test a stable relationship. The results in Table 7 demonstrate that the following factors have a long-term equilibrium relationship. Hence one can see that the variables used are suitable for regression analysis.

\section{Regression Results of Influence Factors An Overall Perspective on China}

In this article, the Ordinary Least Square (OLS) method (Model 1), two-way fixed effect model (Model 2), and random effect model (Model 3) were adopted to analyze the relationship between the national green water efficiency and its influence factors. First of all, three models were established. After constructing the

Table 6. Results of the unit root test.

\begin{tabular}{|c|c|c|c|c|}
\hline \multirow{2}{*}{ Variable } & \multicolumn{2}{|c|}{ The original sequence } & \multicolumn{2}{c|}{ First-order difference sequence } \\
\cline { 2 - 5 } & HT & IPS & HT & $9.9176^{* * *}$ \\
\hline eff & $0.9631^{* *}$ & $9.9176^{* *}$ & $0.0001^{* * *}$ & $-3.1761^{* * *}$ \\
\hline er & $0.7309^{* * *}$ & $-3.1761^{* * *}$ & $0.7089^{* * *}$ & $-3.1761^{* * *}$ \\
\hline lngdp & 0.9679 & $-12.7218^{* * *}$ & $0.9899^{* * *}$ & $-10.5064^{* * *}$ \\
\hline lnsup & $0.1199^{* * *}$ & $-7.3085^{* * *}$ & $-0.7089^{* * *}$ & $-1.7654^{* * *}$ \\
\hline lnfd & 0.8576 & 2.7733 & $0.6646^{* * *}$ & $-6.9000^{* * *}$ \\
\hline lntec & $0.7852^{* * *}$ & 0.8866 & $-0.0359^{* * *}$ & $-5.7254^{* * *}$ \\
\hline sip & $0.8544^{*}$ & $9.2797^{*}$ & $0.1950^{* * *}$ & $6.0316^{* * *}$ \\
\hline tip & $0.8707^{*}$ & $11.8624^{*}$ & $0.1680^{* * *}$ & $-7.6662^{* * *}$ \\
\hline edu & $0.5521^{* * *}$ & $1.2988^{*}$ & $-0.01740^{* * *}$ & $-5.7787^{* * *}$ \\
\hline urb & 0.9668 & $5.2863^{* * *}$ & $0.0515^{* * *}$ & $10 \%, 5 \%$. \\
\hline
\end{tabular}

Note: $* * *, * * *$ respectively reject the assumption that the variable is non-stationary at the significant level of $10 \%, 5 \%$ and $1 \%$ 
Table 7. Results of the cointegration test.

\begin{tabular}{|c|c|c|}
\hline Variable & Kao & Pedroni \\
\hline er & $4.2226^{* * *}$ & $2.9178^{* * *}$ \\
\hline lngdp & $3.4459^{* * *}$ & $1.2110^{* * *}$ \\
\hline lnsup & $3.9443^{* * *}$ & $5.5641^{* * *}$ \\
\hline lnfdi & $3.6964^{* * *}$ & $2.6613^{* * *}$ \\
\hline lntec & $3.9261^{* * *}$ & $2.5371^{* * *}$ \\
\hline sip & $2.0810^{* *}$ & $1.6606^{* *}$ \\
\hline tip & $2.1155^{* *}$ & $1.1692^{* * *}$ \\
\hline edu & $3.8640^{* * *}$ & $3.8067^{* * *}$ \\
\hline urb & $3.8461^{* * *}$ & $1.5491^{*}$ \\
\hline
\end{tabular}

Note: $* * *, * * *$ respectively reject the assumption that the variable is non-stationary at the significant level of $10 \%$, $5 \%$ and $1 \%$.

OLS dummy variables model and fix effect model respectively to make regression, we concluded that the two-way fixed effect model was better than the OLS model. In order to further determine the analysis model of research, the Hausman test was used to compare Model 2 and Model 3. Ultimately, the test result failed to support that the null hypothesis of the Hausman test, namely the random effect model (Model 3), so we rejected the null hypothesis. It was more reasonable to use the two-way fixed effects model (Model 2).

Table 8 summarizes critical variables' descriptive statistics, and eight control variables of interest for our investigation are included. Table 8 further states that the maximum value of eff is 1.02 , whereas the minimum value is 0.167 . The result indicates that an excellent potential for water saving due to China's low green water resources efficiency exists, and the green efficiency of water resources varies widely in each province. The statistics data of all observations demonstrate that it is not just a gulf that exists at the urbanization level - there is a ravine in technology development among thirty provinces and cities. Beyond that, a considerable difference exists in regional water resources abundance of which maximum value is 16113.6, and minimum one is 51.9. That proves that due to the high heterogeneity of such a resource endowment among cities, the distribution of water resources is uneven, making the governance problem of water resources more prominent from the very beginning. Due to an extensive range of planning objectives and strategic oriented management systems in different regions, the allocation of water resources ranged, and the optimal organization has not been carried out yet. Besides, there are significant differences in economic development level and foreign investment because of diverse degrees of openness and economic policies in different cities.

The mixed regression results of the impact effects of environmental regulation are shown in model 1 . Model 2 and Model 3 respectively reflect the regression analysis results of fixed effects and the estimation results of the random-effects model. The regression results of the above three models show that response coefficients of the environmental regulation on green water efficiency are positive and can pass the significant test at the level of $5 \%$, indicating that the enhancement of environmental regulation can significantly promote green water efficiency. The phenomenon means that economic benefits and environmental benefits are both taken into account. Expect for economic development level, water resources abundance, technological progress, and urbanization rate, the influences of other control variables from three models are basically kept with the same direction. The results of the Hausman test show that model 2 is the most suitable for this study, so the following analysis is based on the fixed effects regression model.

Table 8. Variables Description Statistics.

\begin{tabular}{|c|c|c|c|c|}
\hline Variable & Mean & S.D. & Minimum & Maximum \\
\hline eff & 0.453 & 4.036 & 0.167 & 1.02 \\
\hline er & 0.124 & 0.101 & 0.010 & 0.927 \\
\hline gdp & 33452.35 & 25820.29 & 5057.494 & 160981.2 \\
\hline urb & 54.656 & 13.566 & 27.453 & 89.607 \\
\hline fdi & 2.301 & 2.090 & 0.0004 & 12.099 \\
\hline edu & 5.248 & 1.613 & 2.843 & 11.329 \\
\hline tec & 2.767 & 6.634 & 0.127 & 42.519 \\
\hline \multicolumn{5}{|c|}{ Industrial structure } \\
\hline $\operatorname{sip}$ & 43.005 & 8.238 & 15.989 & 61.960 \\
\hline tip & 46.388 & 9.228 & 29.792 & 83.688 \\
\hline sup & 2131.345 & 2509.89 & 51.9 & 16113.6 \\
\hline
\end{tabular}


Then, according to the empirical results in Table 8, we conclude that the green water efficiency will be improved by $12.5 \%$ for each unit increase in the intensity of environmental regulation. It can be observed that environmental regulation can positively affect the improvement of green water efficiency. As for the regression results of control variables, the estimated coefficients of water resources abundance, technological progress, and urbanization are not significant. The fact that the regression coefficient of water abundance is negative demonstrates that in some areas, the dicky condition of natural and the devious location of the economic geography of the regions causes the high cost of development, impediments to the growth and irrational allocation of water resources. As a result, the step to take should include: take regional water resources carrying capacity into account. In other words, it is necessary to consider the ability to support economic, social development and maintain a good ecosystem under reasonable resources development. The reason why the coefficient of the technological progress variable is negative but not significant is that enterprises seek future development and technology innovation investments mainly focus on the expected output, and economic benefits. Thus, the need for green development is ignored. As a result, technology investments do not necessarily promote of green water efficiency and often cause a series of adverse effects. Urbanization level has negative effects on efficiency, which shows that as urbanization is accelerating, its quality needs to be raised in the future. In 2019, the urbanization rate of China was up to $61 \%$ and rose $26.83 \%$ between 2006 and 2019. The urbanization process is so quick but fails to match water resources bearing capacity. At the same time, muscular imbalances among urban agglomeration, industrial layout, and water resources allocation lead to water pollution and other pollutant emissions. The urbanization construction brings severe challenges to the improvement of green water efficiency.

Table 9 presents that the influence of foreign capital utilization for green water efficiency is significant under the 5\% level. With the improvement of laws and regulations and developing trends in green manufacturing technology, in recent years, foreign investments that initially only focused on heavy industry of the extensive type has gradually been used to high-tech industry and been applied to enhance the effectiveness of water resources utilization and control undesirable output, achieving quite remarkable results. The influence coefficients of economic development level, industrial structure change, and educational input on efficiency are significant at the level of $10 \%, 5 \%$ and $1 \%$, respectively.

The green water efficiency increases by 0.052 units for every $1 \%$ increase in the level of economic development. Learning from the change of industrial structure, we find is a relatively significant positive correlation between the tertiary industry and green water efficiency. If the proportion of the third industry rises $1 \%$, green water efficiency will increase by $0.8 \%$. A $1 \%$ drop in the proportion of secondary industry can make green water efficiency increase by $0.6 \%$. The fact shows that with the adjustment of industrial structure, promoting tertiary industry contributes to reducing the pressure of improving water structure and green water efficiency. Compared to the secondary industry, the internal structure of the tertiary industry includes emerging industries such as tourism, environment, and information, which is in accord with the demand for green ecological development. It not only ensures the stable and efficient promotion of the development of the national economy but also has a protective effect on water resources. Over an extended period, the extensive economic development mode leads to serious water consumption, pollution, and the contradiction between the supply and demand of water resources. Therefore, more attention should be paid to the quality in the process of optimizing the industrial structure, and we should strive to seek balance and harmonious development among society, economy, and ecological environment.

Further, the education input has a positive influence on the green water, and when it increases by one percentage, green water efficiency increases by 3.9 percentage. When the whole society advances the capital market to expand funds-raising, the overall cultural level improves year by year. The wider the educational scope is, the stronger the public environmental awareness is, and the more thorough understanding of laws and policies is. To a certain extent, education has reduced obstacles or further development of society, the reform and adjustment of industrial structure, and utilization of water resources.

Table 9. The regression results of green water efficiency.

\begin{tabular}{|c|c|c|c|}
\hline Model & OLS & FE & RE \\
\hline Explanatory variable & Model 1 & Model 2 & Model 3 \\
\hline er & $0.140^{* *}$ & $0.125^{* * *}$ & $0.150^{* * *}$ \\
\hline lngdp & $-0.266^{* *}$ & $0.052^{*}$ & 0.051 \\
\hline lnsup & -0.021 & -0.020 & $-0.030^{* * *}$ \\
\hline lnfdi & $0.012^{* * *}$ & $0.010^{* *}$ & $0.012^{* * *}$ \\
\hline lntec & 0.0001 & -0.005 & -0.001 \\
\hline sip & $-0.003^{* *}$ & $-0.006^{* *}$ & $-0.002^{* *}$ \\
\hline tip & $0.005^{* * *}$ & $0.008^{* *}$ & $0.007^{* * *}$ \\
\hline edu & $0.043^{* * *}$ & $0.039^{* * *}$ & $0.034^{* * *}$ \\
\hline urb & 0.002 & -0.001 & 0.001 \\
\hline cons & $3.479^{* * *}$ & $0.104^{* * *}$ & $0.110^{* * *}$ \\
\hline
\end{tabular}

Note: $* * *, * * *$ indicate the significant difference at the level of $10 \%, 5 \%$ and $1 \%$ respectively. 


\section{Eastern, Central and Western Region}

In order to analyze the differences in the effects of regional influence factors, regression tests were conducted for the eastern, central, and western regions, as represented in Table 8. In order to test the robustness of the research results, the following robust tests were adopted in this research: (1) we changed model data cycle and made regression analysis using the date from 2009 through 2019; (2) among the control variables, "the dependence degree of regional foreign trade - the ratio of import and export volume to GDP" replaced "utilization of foreign capital". The results proved that the influence coefficients only changed in size without affecting the positive and negative effects. When the year that may affect the regression results was removed and the control variables were replaced, the test results showed that the regression results were robust.

In Table 10, apart from the central region, other regions make positive contributions to the efficiency of water resources, and their regression coefficients are significant under the $1 \%$ level. If environmental regulation strength $1 \%$, green water efficiency in western and eastern China will raise $8.35 \%$, $10.9 \%$, respectively. The regression coefficient of the central region is negative but not significant, because policies and environmental regulations can not fully be adjusted according to local conditions. In another way, the intensity of regulations, industrial structure, economic development, resource endowment, and other factors have a role in environmental regulation. In the eastern region, many enterprises are shifting to sustainable development mode that vigorously supports the development of emerging technology industries with low energy consumption and high output. For example, the power, chemical, metallurgy, and paper industries prefer cleaner production, attempting to save capital and reduce consumption. Therefore, the whole society falls into a peaceful and positive atmosphere conducive to promoting green water efficiency. However, regional interaction accelerates the industrialization process of the central region who achieves high-speed development, but it always ignores green development. The existing environmental regulations themselves have a so-called double-edged sword effect, which means the misdirected environment regulations probably have a negative effect. China should regard the intensity and policy design of environmental regulations in the future.

The regression results of the eastern region vary from those of the whole country. Except for the level of economic growth, water resources abundance, and industrial structure, the regression coefficients of other variables have passed the significance test at the $1 \%$ level. Due to more abundant educational resources and the improvement of urbanization quality, technological superiority is evident in eastern China. Though, there is still much room for further progress in improving the efficiency of green water resources.
Unlike the eastern and western regions, in the test, the effect of economic development level and technological progress is significantly negative, indicating that when some companies in central China invest in the latest technology, they ignore problems, such as energy conservation or emission reduction. Therefore, the economic development is speeding up, with low quality.

The coefficients of water resources abundance and foreign capital utilization in western regions are not significant, presumably because of the fragility of the ecological environment, nonuniform spatial distribution of water resources, relatively backward economy, insufficient technology, and lack of external communication. At the same time, the rapid development of economy brings much pollution to the environment. The weak water resources protection and the fragile ecology would drive up low green water efficiency. Technological progress that increases by 1 percent will give rise to increase by 0.054 units in green water efficiency. Green water efficiency is more sensitive to the adjustment and upgrading of industrial structures is because technological innovation investment and the upgrading of industrial structures promote energy conservation, and pollution reduction in remote areas. With the advancement of the urbanization process in western China, green water efficiency has gradually been enhanced. Each additional percentage point in the urbanization level means a corresponding increase in the efficiency value of green water resources by $1 \%$. Due to the low overall level of urbanization, the output benefit of production factor agglomeration is higher than the cost.

Improving green water efficiency is a complex systematic project. Aimed at solving these problems, we need to take more measures and master core technologies to breakthrough.

Compared with results concluded in existing literature, this paper has the following new findings: (1) There is no final conclusion on the impact of environmental regulation that is often put into regression analysis as a control variable for a significance test. This paper takes environmental regulation as an explanatory variable to analyze its impact on national and regional green water efficiency. The results show that except for the western region, environmental regulation has a significant positive impact on the efficiency of green water resources, indicating that environmental regulation has a highly crucial influence on the coordinated development of the economy and environment. Effectively strengthening environmental regulation and perfecting policy systems are necessary to improve green water efficiency in China. (2) To construct the DEA-SBM model, one has to select the input index and output index of water resources. The utilization of water resources is combined with the measurement of sewage control level in the DEA-SBM model, which overcomes the problem of paying too much attention to the economic attribute of the water resources efficiency 
Table 10. The regression results of green water efficiency in different regions.

\begin{tabular}{|c|c|c|c|c|}
\hline Explanatory variable & Eastern region & Central region & Western region & The whole country \\
\hline er & $0.0835^{* * *}$ & -0.038 & $0.109^{* * *}$ & $0.125^{* * *}$ \\
\hline lngdp & 0.102 & $-0.125^{* * *}$ & $-0.145^{* *}$ & $0.052^{*}$ \\
\hline lnsup & 0.024 & 0.018 & 0.001 & -0.020 \\
\hline Infdi & $0.028^{* * *}$ & $0.030^{* *}$ & 0.001 & $0.010^{* *}$ \\
\hline lntec & $0.360^{* * *}$ & $-0.136^{* * *}$ & $0.054^{* * *}$ & -0.005 \\
\hline sip & -0.009 & -0.001 & $0.011^{* *}$ & $-0.006^{* *}$ \\
\hline tip & 0.011 & 0.002 & $0.008^{* *}$ & $0.008^{* *}$ \\
\hline edu & $0.081^{* * *}$ & $0.019^{* * *}$ & $0.012^{*}$ & $0.039^{* * *}$ \\
\hline urb & $0.023^{* * *}$ & $0.011^{* *}$ & $0.010^{* *}$ & -0.001 \\
\hline cons & $1.989^{* *}$ & $0.030^{* * *}$ & $0.607^{* * *}$ & $0.104^{* * *}$ \\
\hline Individual fixed & yes & yes & yes & yes \\
\hline Time fixed & yes & yes & yes & 126 \\
\hline observations & 154 & 140 & 0.278 & yes \\
\hline adj-R & 0.662 & 0.334 & 420 \\
\hline
\end{tabular}

Note: $*, * *, * *$ indicate the significant difference at the level of $10 \%, 5 \%$ and $1 \%$ respectively.

index in the existing research. This paper measures the redundancy of water resources input and unexpected output in the whole country and 30 provinces and finally puts forward strategies to improve green water efficiency in different provinces. Many investigators have carried out several studies that are still far from complete at present. So classified discussion is also the essential part of the earth extermination operation to make sure environmental laws and regulatory policies are adjusted according to local conditions. This paper enriches the content of green water efficiency, the research method is innovative, and the conclusion is more scientific.

\section{Conclusions and Implications}

\section{Conclusions}

Water is the vital link in the development of society, economy, and watershed ecology. The relationship between environmental regulation and green water efficiency is a hot research issue, which is significant for society's sustainable development, and is the key to realizing the coordinated development of economic growth, environmental protection, and effective utilization of resources. High quality is an integral part of green development, and the concept of "highcoordination" should be quoted in the water efficiency model. In this paper, SBM is used to measure national and regional green water efficiency, and the regulating effect of environmental regulations on green water efficiency is discussed. The main conclusions are as follows:
First, from 2006 to 2019, green water efficiency rises in volatility at a national level and experiences three stages successively: decline, steady increase and speedup periods. The highest potential has not been reached yet. As a whole, the eastern part follows a trend similar to the tendency of national green water efficiency, while the Midwest exhibits an "interactive" phenomenon. In contrast, the overall efficiency of the east had a certain advantage.

Second, in the regression test at the national level, environmental regulations have a significant positive effect. Apart from the central, environmental regulations in eastern and western China also encourage green water efficiency.

Third, the effects of each control variable at different regional levels are disparate. The eastern region has absolute advantages in technology, education, urbanization, and openness, which contribute to green water efficiency. Environmental regulations and technological innovation in the central region are the critical breakthrough points. Answering the call of Great Western Development Strategy and taking advantage of relevant policies, the western region still needs to focus on the scientific and technological research investment, optimization of industrial structure and education, in order to realize effective utilization of resources and overcome shortcomings.

\section{Suggestions}

According to the above conclusion, some advice is proposed. Firstly, environmental regulation plays an essential role in improving the efficiency of green water 
resources of the whole country and region. In order to promote green environmental protection and highquality economic development, environmental carrying capacity and water resources bearing capacity must be considered in industrial plans that need to focus on the introduction of projects with high utilization of water resources and sewage treatment technology. Besides, when initiating preferential policy on attracting business and investment, local governments strictly review the project's water requirements and take green water resources efficiency as a critical content to make progress. Then an evaluation system for water resource utilization and sewage discharge efficiency should be established. It is necessary to set up a directory for Chinese businesses with high efficiency of green water resources to provide learning objects for other enterprises. Secondly, the enforcement of environmental regulation should not be "one-size-fitsall". Therefore, when designing policies and strategies, consider regional differences according to local conditions to avoid generalities, pay attention to plan multi-type and multi-level environmental regulations, and realize differentiated environmental regulations. Targeted and categorized regulatory policies are able to drive green development to their fullest potential. Thirdly, external factors play an increasing role in improving the efficiency. We should think highly of the promoting effects of external factors such as level of opening, technological progress, education level, and urbanization rate. From the perspective of the three regions, the eastern region belonging to relatively well-developed areas is significantly constrained by resources and the environment. The government should continue to promote scientific and technological innovation and raise the opening up level to promote new knowledge and technology transformation and make further progress in scientific water use and systematic governance. At the same time, enterprises have to enhance the ability of independent learning and innovation to improve green water efficiency. The central region strengthens the concept of green development and actively introduces advanced experience and technology to strengthen water resources recycling. Due to the relatively backward economy, the improvement of green water efficiency in the western region is restricted by the weak production foundation and level of water resources marketization. It is necessary to strengthen the interaction and development of the secondary and tertiary industries. Based on the opportunity of the western development, adopt policy advantages to strengthen the infrastructure construction and the investment level of science and technology R\&D. Last but not least, to improve resources efficiency, the move to accelerate the construction of a modern green water resources industrial structure system has been urgent. Consider optimizing the distribution efficiency of national water resources from some aspects, such as scientific and technological innovation, high-quality economic development, industrial structure optimization, and continuous education.

\section{Research Limitations and Prospects}

There are still several shortcomings in this paper, which will be the content of subsequent research:

(1) There is a lack of discussion on the classification of the command-and-control, informal environmental regulations, and their impact on green water efficiency because the paper fails to find quantitative indicators that reasonably reflect their features.

(2) The synergistic effects of different environmental regulations have not been studied. In different stages of economic development, designing rational environmental regulation and optimizing its structure as the case may be are necessary so that local governments could assemble environmental regulations tools optimally.

(3) The current research lacks a complete theoretical mechanism and empirical framework. In the future, the interaction mechanism can be modeled on the basis of existing research. The model used to measure green water efficiency in this paper can be made up. Models with different inputs, desirable and undesirable outputs may yield mixed results. There is much room for improvement in the accuracy of green water efficiency.

(4) To study regional green water efficiency, this paper divides China into three major economic zones: eastern, central, and western. However, the three regions cover a wide range, which is not conducive to obtaining accurate research results. Subsequent research can try different methods to study in order to make the empirical results more precise.

\section{Acknowledgment}

The paper was supported by the Planning Fund of Education Ministry for Humanities and Social Sciences (NO: 18YJAZH010) and the Fundamental Research Funds for the Central Universities (NO: ND2021005).

\section{Conflict of Interest}

The authors declare no conflict of interest.

\section{References}

1. DONG F., LI J., WANG Y., ZHANG X., ZHANG S. Drivers of the decoupling indicator between the economic growth and energy-related $\mathrm{CO}_{2}$ in China: a revisit from the perspectives of decomposition and spatiotemporal heterogeneity. Science of the Total Environment, 685, 631, 2019a.

2. PANG R., DENG Z., HU J. Clean energy use and totalfactor efficiencies: an international comparison. Renewable and Sustainable Energy Reviews, 52, 1158, 2015. 
3. CHARNES A., COOPER W.W., RHODES E. Measuring the efficiency of decision making units. Europe Journal of Operational Research, 2 (6), 429, 1978.

4. SUEYOSHI T., GOTO M. Returns to scale and damages to scale on U.S. fossil fuel power plants: radial and nonradial approaches for DEA environmental assessment. Energy Economy, 34 (6), 2240, 2012.

5. LI M., PAN X., YUN S. Do the national industrial relocation demonstration zones have higher regional energy efficiency? Applied Energy, 306, Article No.117914, 2022.

6. WANG R., TIAN Z., REN F. Energy efficiency in China: optimization and comparison between hydropower and thermal power. Energy, Sustainability and Society, 11(1), $1,2021$.

7. ZHOU M., WANG T., YAN L., XIE X. Heterogeneity in the influence of fiscal decentralization and economic competition on China's energy ecological efficiency. Resource Science, 41 (3), 532, 2019.

8. DENG G., LI L., SONG Y. Provincial water use efficiency measurement and factor analysis in China: Based on SBMDEA model. Ecological Indicators, 69, 12, 2016.

9. CAO L., FAN L., LEI S. Fiscal decentralization, environmental regulation and agricultural eco-efficiency. Statistics \& Decision, 19, 138, 2021.

10. LUO N., WANG Y. Fiscal decentralization, environmental regulation and regional eco-efficiency. China Population, Resources and Environment, 27 (4), 110, 2017.

11. ZHANG R. An empirical analysis on the efficiency of financial support in emerging industries. Statistics \& Decision, 21, 102, 2013.

12. SEXTON T.R., SILKMAN R.H., HOGAN A.J. Data envelopment analysis: critique and extensions. Evolutionary Anthropology: Issues, News, and Reviews, 1986 (32), 73, 1986

13. DOYLE J., GREEN R. Efficiency and cross-efficiency in DEA: derivations, meanings and uses. Journal of Operational Research Society, 45 (5), 567, 1994.

14. SUN C., LIU Y. Analysis of the spatial-temporal pattern of water resources utilization relative efficiency based on DEA-ESDA in China. Resources Science, 31 (10), 1696, 2009.

15. DING X., HE J., WANG L. Inter-provincial water resources utilization efficiency and its driving factors considering undesirable outputs. China Population, Resources and Environment, 28 (1), 157, 2018.

16. XIE Y., SONG Y. Spatiotemporal analysis of urban water use efficiency of the Yangtze River Economic Zone in China: based on undesirable super-efficiency EBMDEA model. Journal of Coastal Research, 103 (sp1), 458, 2020.

17. SUN C., MA Q., ZHAO L. Analysis of driving mechanism based on a GWR model of green efficiency of water resources in China. Acta Geographica Sinica, 75 (5), 1022, 2020.

18. ZHANG G., WU H., LIU Y., ZHOU Z. Measurement and the spatial interaction analysis of the water resources comprehensive utilization efficiency in China. The Journal of Quantitative \& Technical Economics, 37 (8), 123, 2020.

19. WANG X., ZHAO L. Agricultural water efficiency and influencing factors: SFA analysis based on provincial panel data from 1997-2006. Issues in Agricultural Economy, 3, $10,2008$.

20. HU J.L., WANG S.C., YEH F.Y. Total-factor water efficiency of regions in China. Resources Policy, 31 (4), 217, 2006.
21. DONG Z., YU E., QIU L., GE C. Water efficiency evaluation of the provincial regions in China based on DEA model. Ecological Economy, 10, 43, 2012.

22. ZHANG X., ZHONG R. Empirical research on the efficiency, spatial spillover and impact factors of irrigation water. Journal of South China Agricultural University (Social Science Edition), 15 (4), 20, 2015.

23. SUN D., YU J., LIU L., WANG H. Efficiency evaluation for industrial water use and analysis of spatialtemporal differences in the Yangtze River Delta urban agglomeration. Resources and Environment in the Yangtze Basin, 27 (9), 1901, 2018.

24. PAN Z., LI Z., XU C. Environmental regulation and efficiency improvement of region green water sources: An empirical analysis of Yangtze River economic belt. The World of Survey and Research, 11, 10, 2020.

25. KARAGIANNIS G., SARRIS A. A comparison of SFA and DEA scale efficiency estimates: The case of Greek fresh fruits producers. Indian Economic Review, 39 (1), 149, 2004

26. KANEKO S., TANAKA K., TOYOTA T., MANAGI S. Water efficiency of agricultural production in China: Regional comparison from 1999 to 2002.International Journal of Agricultural Resources, Governance and Ecology, 3 (3/4), 231, 2004.

27. CHEN G., BAI Y. Regional differences in Total-Factor Industrial Water Efficiency based on a Stochastic Frontier Approach. Resource Science, 35 (8), 1593, 2013.

28. ZHANG F., WANG H., XUE H. China's industrial green total factor water efficiency under the constraints of environment and resource. China Environment Science, 40 (11), 5079, 2020.

29. ZHANG X., YU F .Analysis of the matching status between economic development and water resources in the Yellow River Basin. China Population, Resources and Environment, 22 (10), 1, 2012.

30. ZHANG X., LI Y., WU W. Evaluation of urban resource and environmental efficiency in China based on the DEA model. Journal of Resources and Ecology, 5 (1), $11,2014$.

31. TONE K., SAHOO B.K. Scale, indivisibilities and production function in data envelopment analysis. International Journal of Production Economics, 84 (2), 165,2003

32. WANG H., LALL S. Valuing water for Chinese industries: a marginal productivity analysis. Applied Economics, 34 (6), 759, 2002.

33. ZHANG J., WU G., ZHANG J. Estimation of China's provincial physical capital stock: 1952-2000. Economic Research Journal, 10, 35, 2004.

34. EUN Y.B., JAI S.M. The role of industrial policy in the economic development of Uzbekistan. Post-Communist Economies, 31 (2), 240, 2019.

35. TELLE K., LARSSON J. Do environmental regulations hamper productivity growth? How accounting for improvements of plants' environmental performance can change the conclusion. Ecological Economics, 61 (2), 438, 2006.

36. LI J., MA X. Econometric analysis of industrial water use efficiency in China. Environment, Development and Sustainability, 17 (5), 1209, 2015.

37. HOU Y., LQBAL W., SHAIKH G.M., LQBAL N., SOLANGI Y.A., FATIMA A. Measuring energy efficiency and environmental performance: A case of South Asia. Processes, 7 (6), 325, 2019. 
38. ZHANG G., CUI J. A general inverse DEA model for nonradial DEA. Computers \& Industrial Engineering, 142, Article No.106368, 2020.

39. FENG Z., CHEN W. Environmental regulation, green innovation, and industrial green development: An empirical analysis based on the spatial durbin model. Sustainability, 10 (1), 223, 2018.

40. SUN C., TANG W., ZOU W. Research on the coordinating relationship among rural water poverty,urbanization and industrialization process in China. China Soft Science, 7, 86, 2013.

41. SELVAKUMAR S., CHANDRASEKAR N., KUMAR G. Hydrogeochemical characteristics and groundwater contamination in the rapid urban development areas of Coimbatore, India. Water Resources and Industry, 17, 26, 2017.

42. WANG W., WANG Y., XU R. The law and influencing factors of industrial structure change in the Yellow River basin under water resource constraints. Journal of Industrial Technological Economics, 39 (6), 138, 2020.

43. LIU S., KAO C. A slacks-based measure model for calculating cross efficiency in data envelopment analysis. Omega, 95, Article No. 102192, 2020.

44. CHEN S., GOLLEY J.' Green' productivity growth in China's industrial economy. Energy Economics, 44, 89, 2014.

45. LIM S., ZHU J. Primal-dual correspondence and frontier projections in two-stage network DEA models. Omega, 83, 236, 2018.

46. NASO P., HUANG Y., SWANSON T. The impact of environmental regulation on Chinese spatial development. Economics of Transition and Institutional Change, 28 (1), 161, 2020.

47. WANG C., ZHANG Y. Does environmental regulation policy help improve green production performance? Evidence from China's industry. Corporate Social Responsibility and Environmental Management, 27 (2), 937, 2020.

48. ZHANG L., LONG R., CHEN H., HUANG X. Performance changes analysis of industrial enterprises under energy constraints. Resources, Conservation and Recycling, 136, 248, 2018.

49. ZHAO L., SUN C., LIU F. Interprovincial two-stage water resource utilization efficiency under environmental constraints and spatial spillover effects in China. Journal of Cleaner Production, 164, 715, 2017.

50. DING X., TANG N., HE J. The threshold effect of environmental regulation, FDI agglomeration, and water utilization efficiency under "double control actions" An empirical test based on Yangtze River economic belt. Water, 11 (3), 452, 2019.

51. HAO Y., DENG Y., LU Z., CHEN H. Is environmental regulation effective in China? - Evidence from city-level panel data. Journal of Cleaner production, 188, 966, 2018.
52. SHANG Y., LU S., LI X., SUN G., SHANG L., SHI H., LEI X., YE Y., SANG X., WANG H. Drivers of industrial water use during 2003-2012 in Tianjin, China: A structural decomposition analysis. Journal of Cleaner Production, 140, 1136, 2017.

53. REN C.F., GUO P., LI M., GU J.J. Optimization of industrial Structure considering the uncertainty of water resources. Water Resources Management, 27 (11), 3885, 2013.

54. RUSIAWAN W., TJIPTOHERIJANTO P., SUGANDA E., DARMAJANTI L. Assessment of green total factor productivity impact on sustainable indonesia productivity growth. Procedia Environmental Sciences, 28, 493, 2015.

55. PANG R., DENG Z., HU J. Clean energy use and total-factor efficiencies: An international comparison. Renewable and Sustainable Energy Reviews, 52, 1158, 2015.

56. LQBAL W., ALTABLBE A., FATIMA A., ALI A., HOU Y. A DEA approach for assessing the energy, environmental and economic performance of top 20 industries countries. Processes, 7 (12), 902, 2019.

57. COOPER W.W., PARK K.S., PASTOR J.T. RAM: a range adjusted measure of inefficiency for use with additive models, and relations to other models and measures in DEA. Journal of Productivity Analysis, 11 (1), 5, 1999.

58. REN Y.,FANG C.,LIN X.,SUN S.,LI G.,FAN B. Evaluation of the eco-efficiency of four major urban agglomerations in coastal eastern China. Journal of Geographical Sciences, 29 (8), 1315, 2019.

59. LEE T., YEO G., THAI V.V. Environmental efficiency analysis of port cities: slacks-based measure and data envelopment analysis approach. Transport Policy, 33, 82, 2014.

60. SONG M., WANG R., ZENG X. Water resources utilization efficiency and influence factors under environmental restrictions. Journal of Cleaner Production, 184, 611, 2018

61. SUN C., LIU Y. Analysis of the spatial-temporal pattern of water resources utilization relative efficiency based on DEA-ESDA in China. Resource Science, 31 (10), 1696, 2009.

62. RENZETTI S., DUPONT D.P. Measuring the technical efficiency of municipal water suppliers: The role of environmental factors. Land Economics, 85 (4), 627, 2009.

63. WANG G., XIAO C., QI Z., MENG F., LIANG X. Development tendency analysis for the water resources carrying capacity based on system dynamics and improved fuzzy comprehensive evaluation method in the Changchun city, China. Economical Indicators, 122, Article No.107232, 2021.

64. SUN X., GUO C., CUI J. Research on evaluation method of water resources carrying capacity based on improved TOPSIS model. La Houille Blanche, 106 (5), 68, 2020. 
